\title{
Determining the parameters of the trajectory of the bucket of mining quarries excavators
}

\author{
Valerii Tytiuk ${ }^{1, *}$, Kamal Khandakji ${ }^{2}$, Galina Sivyakova ${ }^{3}$, Nadezhda Karabut $^{1}$, Oleksii Chornyi ${ }^{4}$, and Victor Busher $^{5}$ \\ ${ }^{1}$ Kryvyi Rih National University, 11 Vitalii Matusevych Str., Kryvyi Rih, 50027, Ukraine \\ ${ }^{2}$ Tafila Technical University, Department of Electrical Power and Mechatronics Engineering, Jordan \\ ${ }^{3}$ Karaganda State Industrial University, Department of Power Industry and Automation of Technical Systems, Kazakhstan \\ ${ }^{4}$ Kremenchuk Mykhailo Ostrohradskyi National University, Institute of Electromechanics, Energy Saving and Automatic Control \\ Systems, 20 Pershotravneva Str., Kremenchuk, 39600, Ukraine \\ ${ }^{5}$ National University Odessa Maritime Academy, Department of Electrical Engineering and Electronics, 8 Didrikhsona Str., Odessa, \\ 65000, Ukraine
}

\begin{abstract}
The bucket positioning of the excavator in three-dimensions (3-D) is the precondition of the robotic excavator starting automatized works. The electric excavator is one of the most widely used machinery in the mining industry, mainly due to its versatility and portability. Among the tasks performed by the excavator, there is a significant number of repetitive movements associated with moving the bucket to the unloading point and back to the face. Using automated functions to perform such repetitive tasks will not only significantly increase overall productivity, but also reduce energy consumption. This research is carried out to create a method of coordinate control of electric drives of the boom, dipper stick, and bucket of an electric excavator to perform accurate and efficient work. On the basis of the kinematic analysis of the excavator's attachment system, the trajectory of the end of the working body can be determined from the point of view of the coordinated movement of the electric drives of the main mechanisms of the excavator. Thus, the complex algorithm of the excavator bucket 3-D position control can be carried out by coordinated control of the movement of three separate electric drives. This coordinate control algorithm was tested on the example of the EKG-8I excavator, and the results of the verification showed that this developed control method can satisfactorily perform the function of automatic control of the bucket position in threedimensional space. Optimization of control will be further carried out based on the analysis of the energy efficiency of various possible trajectories.
\end{abstract}

\section{Introduction}

The excavator is an earth-moving machine designed for excavation of soil with lifting, moving it and unloading it into a dump or onto vehicles. Excavators play an important role in opencast mining of ore deposits, are used in land reclamation and road construction, dredging and port work, and the building of defensive constructions.

The most powerful excavators are used in open pit mining both for stripping operations and for reloading the rock mass and forming dumps. Discontinuous singlebucket excavators are most widely used in these production conditions. Discontinuous (cyclic) excavators perform work operations in a specific sequence, forming a full working cycle; the movement of the machine itself is carried out after performing several cycles.

They are made with various types of interchangeable working equipment (Fig. 1), but in any case, the working body has rigid connections with the machine mechanisms, which limits its degrees of freedom.
In the mining industry, the production of new generation equipment is characterized by a functional and constructive combination of electromechanical converters with energy and information components with a high level of organization of control processes, i.e., the creation of mechatronic complexes. A modern excavator is a complex of interconnected electrical, mechanical, electromechanical and electronic systems of high complexity [1]. This allows us to consider the technological units of the excavator as mechatronic modules, combined into a complex mechatronic complex [2].

For mechatronic complexes of mining machines, due to their significant installed capacity, the energy efficiency of their functioning is of great importance. Increasing the efficiency of using electrical energy in industry and, consequently, mechatronic systems of mining machines is a determining factor in the development of technical systems in the near future [3].

In this regard, the study and modeling of energy processes is of decisive importance in the design of mechatronic systems for mining machines.

\footnotetext{
$\overline{{ }^{*} \text { Corresponding author: tytiuk@knu.edu.ua }}$
} 


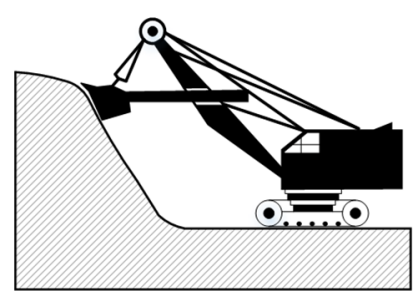

a)

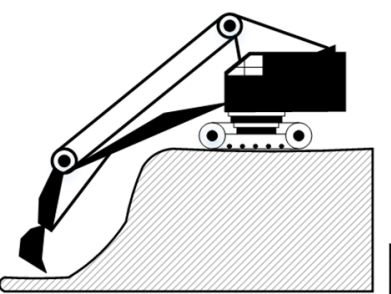

b)

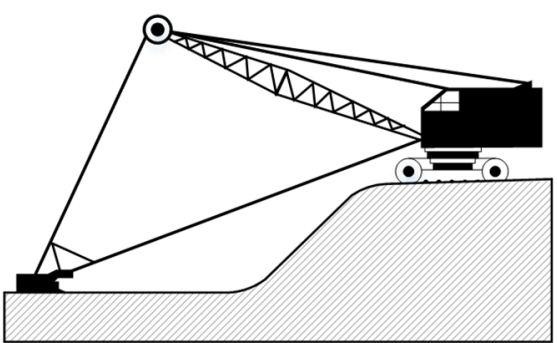

c)

Fig. 1 The main types of single-bucket excavators: a) a power shovel; b) a backhoe; c) a dragline.

\section{Literature review}

At present, this task is becoming extremely urgent due to the fundamental renewal of both the power equipment of the excavator electric drives and the technical means of control. Energy calculation remains the most difficult and critical stage in the design of mechatronic systems. At present, it is carried out using separate methods [4], which do not take into account the settings of regulating devices and the features of power converters.

Analysis of modern scientific and technical literature indicates that at present there is no general theoretical approach to the analysis and synthesis of control systems that ensure the rational use of electricity in mechatronic systems, and effective models of energy processes for the study and design of mechatronic systems. Modern methods of designing mechatronic systems make it possible to synthesize the structure with a given quality of transient processes [5, 7]. Standard methods for adjusting the regulators of slave circuits of electric drive systems - modular and symmetric optima [6,7], do not take into account not only energy losses and the influence of power supplies, but also the different physical essence of control processes in a mechatronic system. For electric drive systems with thyristor and transistor energy converters, the operation of which is characterized by harmonic distortions of the shape of currents and voltages, both calculations and measurements of energy characteristics turn out to be difficult, since specialized measuring instruments for these purposes are not produced, and models and estimates of the parameters of electric power processes for nonlinear systems do not have unambiguous and generally accepted definitions [8, 9]. The synthesis of control systems that are optimal in terms of the minimum energy consumption is a complex problem, which in many cases does not have an unambiguous solution [10]. In addition, as shown in [11], the minimum energy consumption is not identical to the increase in the energy efficiency of technical systems.

The synthesis of control systems optimal in terms of energy efficiency is significantly hampered by the lack of scientific papers devoted to a comprehensive analysis of the interrelated movements of excavator mechanisms to implement the desired trajectories of the bucket movement during the working cycle. A significant part of well-known scientific works is devoted to the study of individual excavator mechanisms, isolated from the general complex. The interconnected operation of the electric drives for lifting and head during the digging process is considered in articles $[12,13]$, but the operation of the same mechanisms in other sections of the trajectory is not considered.

Thus, there is a contradiction between the practical need to increase the energy efficiency of industrial mechatronic systems, on the one hand, and the limited capabilities of modern methods of analysis and synthesis and control algorithms for solving this problem. An important distinguishing feature of mechatronic devices is the presence of a perfect system for monitoring and controlling the position of the working bodies [14]. But it should be noted that the modern equipment of mining excavators does not contain a system for controlling the position of the working body. These functions are performed by the excavator operator by the joint or separate movement of individual elements of the kinematic chain with visual control of the result, which significantly reduces the possibility of automatic optimization of productivity, energy consumption, increases the requirements for the operator's qualifications.

The solution to this problem is possible only with the correct formulation of a complex of interrelated scientific and practical problems: the formation of indicators of the energy efficiency of mechatronic systems of mining machines, taking into account both energy costs and changes in productivity when implementing various control laws; automating the development of optimal trajectories for moving the working bodies of mechatronic systems in space; implementation of highquality positional control systems that ensure the development of these trajectories; verification of the obtained technical solutions and their approbation in industry.

The formulated range of tasks cannot be considered in detail within one publication. The aim of this work is to develop a mathematical model of the mechanical part of open-pit excavators, which provides a solution to the inverse kinematics problem, i.e. establishing the required law of motion of individual mechanisms of a mining excavator to ensure a given trajectory of movement of the working body, which will further determine and optimize energy and technical and economic indicators when performing a working cycle. 


\section{Excavator design features. Excavator- related coordinate systems}

The most common type of powerful mining excavators in the conditions of Ukrainian mining enterprises are shovel excavators - EKG-5, EKG-8, EKG-10, EKG-12.5, EKG20. These excavators have a similar design of the main mechanisms, differing in geometric dimensions and minor structural elements.

The further presentation will be carried out in relation to the EKG-8I excavator, in our opinion, the most common model of a mining excavator in the conditions of the Kryvyi Rih iron ore basin. In fig. 2 shows the layout of the equipment on the platform of the EKG-8I excavator.

The main movements of the excavator, performed during the execution of the working cycle - lifting / lowering the bucket when digging and unloading (hoisting mechanism); a linear movement of the dipper stick during digging and unloading (crowd mechanism) and rotation of the platform to the place of unloading and digging (swing mechanism). We do not mention the mechanism of the excavator's travel, since the movement of the excavator is carried out separately from the working cycle.

The formulation of the problem of controlling the movement of the working bodies of an excavator requires the solution of kinematic problems typical for mechatronic systems: determining the position of the bucket in space for the given values of the positions of the crowd, hoisting and swing mechanisms (the direct problem of the kinematics of the mechanical subsystem) and determining the positions of the crowd, hoisting and swing mechanisms for a given position bucket in space (the inverse problem of the kinematics of the mechanical subsystem). The main difficulty in determining the position of the working bodies in space is that individual mechanisms perform different types of movements, and the axes of rotation of individual mechanisms do not coincide with each other.

Figure 3 a simplified kinematic diagram of the mechanisms of a power shovel excavator is presented. The position in space of the excavator bucket is fully described by the three-dimensional coordinates of the digging point $K$.

The lift of the bucket is carried out by changing the angle of rotation around the axis passing through point 1 , perpendicular to the plane of the figure.

The extension and retraction of the bucket occur with linear movement in the saddle bearing located at point 1 and is carried out by the linear movement of the dipper stick $L_{N}$. The platform rotates around a vertical axis passing through its center of mass and is carried out by changing the rotation angle $\varphi_{R}$. Figure 4 illustrates the relative position of the boom and bucket of an excavator at various limiting values of the angle $\varphi_{P}$ of the bucket and the linear movement of the dipper stick.

Thus, the controls action can be represented by the vector $u=\left[L_{N} \varphi_{R} \varphi_{P}\right]$, the state vector, that describing the position of the bucket, is given by the Cartesian coordinates of the digging point $s=\left[\begin{array}{lll}X & Y & Z\end{array}\right]$.

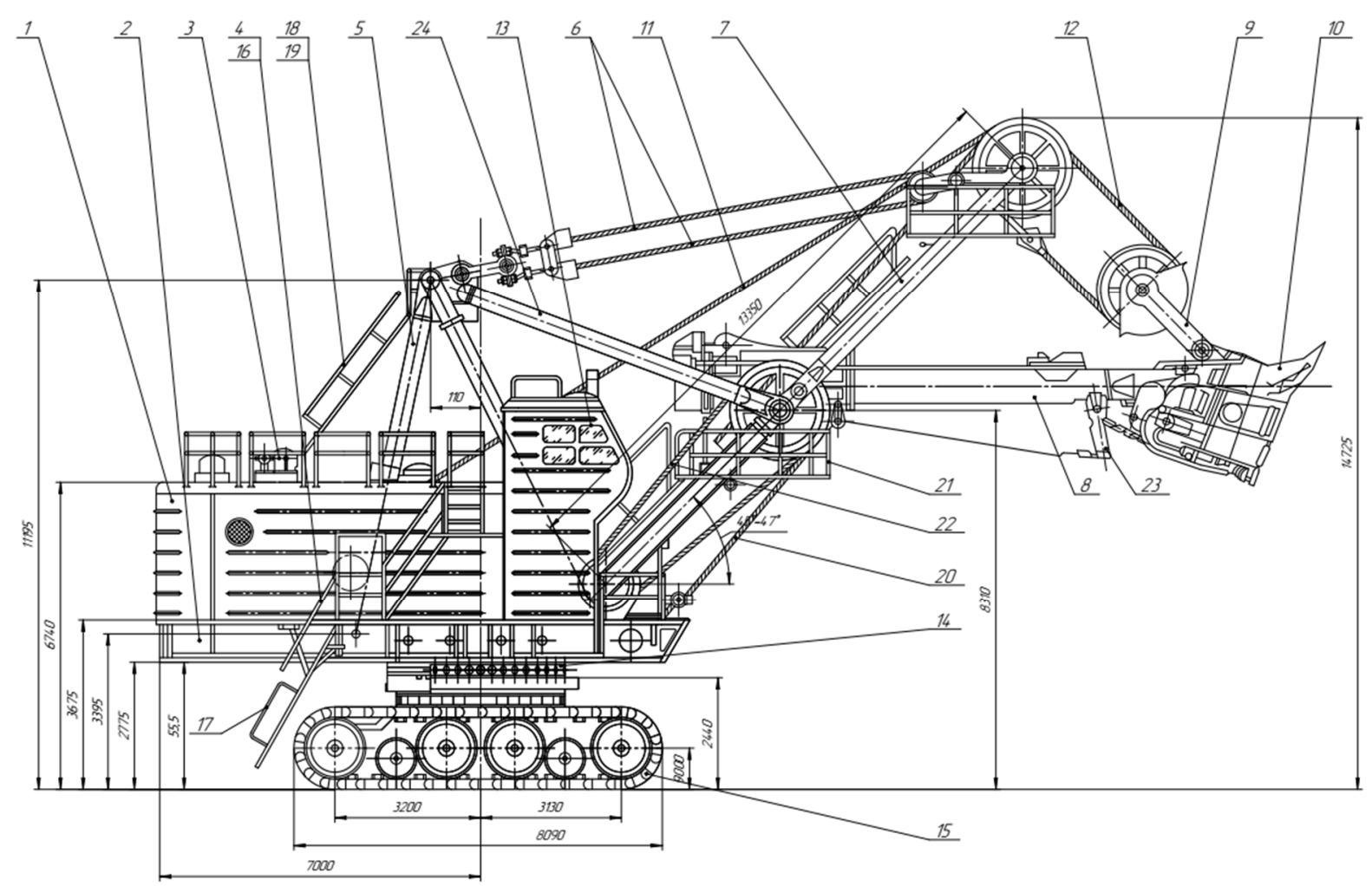

Fig. 2. Equipment layout and geometrical dimensions of the EKG-8I excavator. 1 - revolving deck; 2 - body; 3 - auxiliary winch; 4 steps; 5 - two-legged stand; 6 - cables; 7 - boom; 8 - dipper stick; 9 - bucket suspension; 10 - bucket; 11 - rope; 12 - hoisting rope; 13 - driver's cab; 14 - roller circle; 15 - undercarriage; 16 - fence; 17 - entrance steps; 18 - steps; 19 - fence; 20 - rope; 21 - platform on the boom; 22 - rope. 


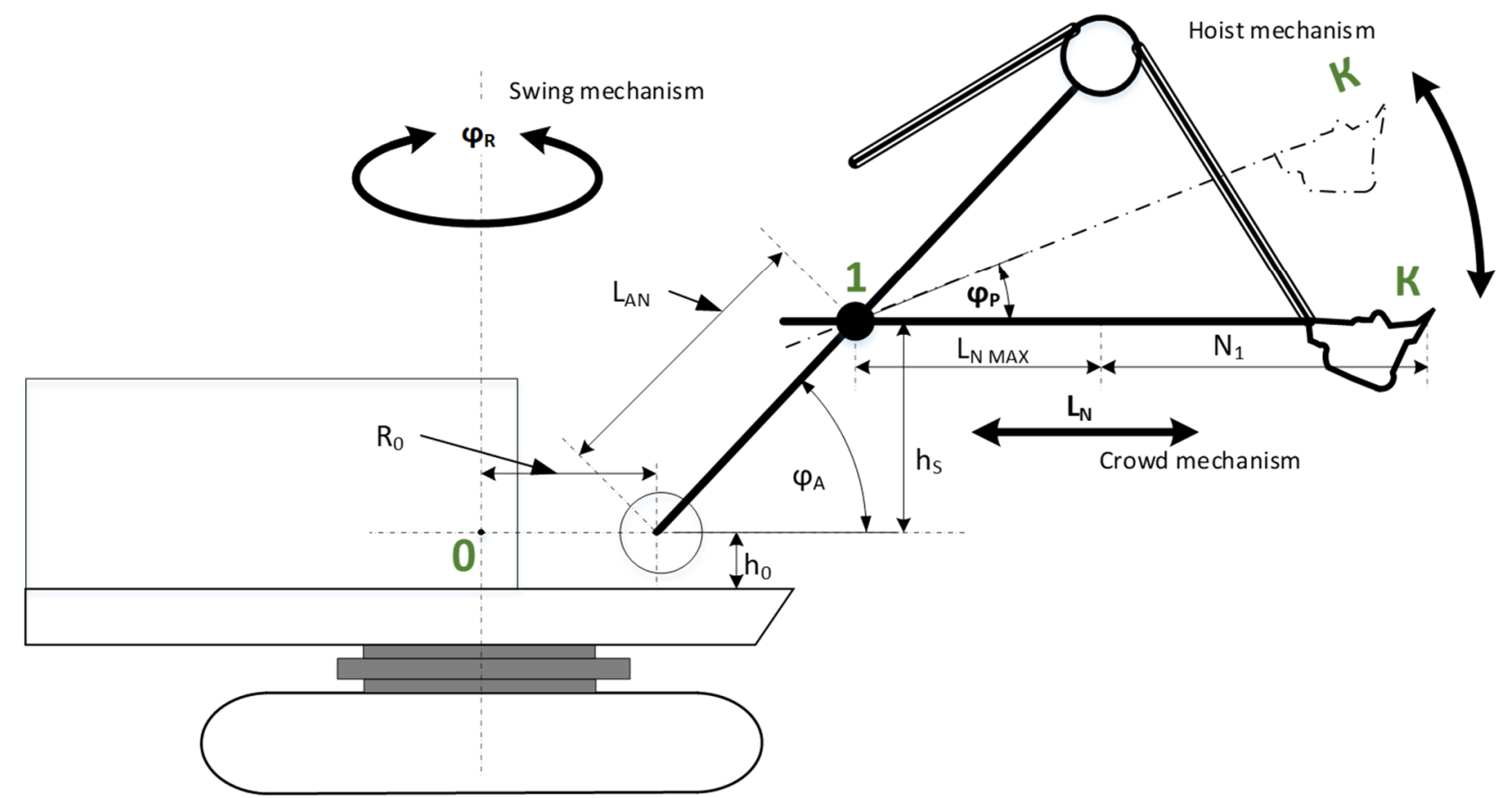

Fig. 3. Simplified kinematic diagram of the mechanisms of a power shovel excavator.
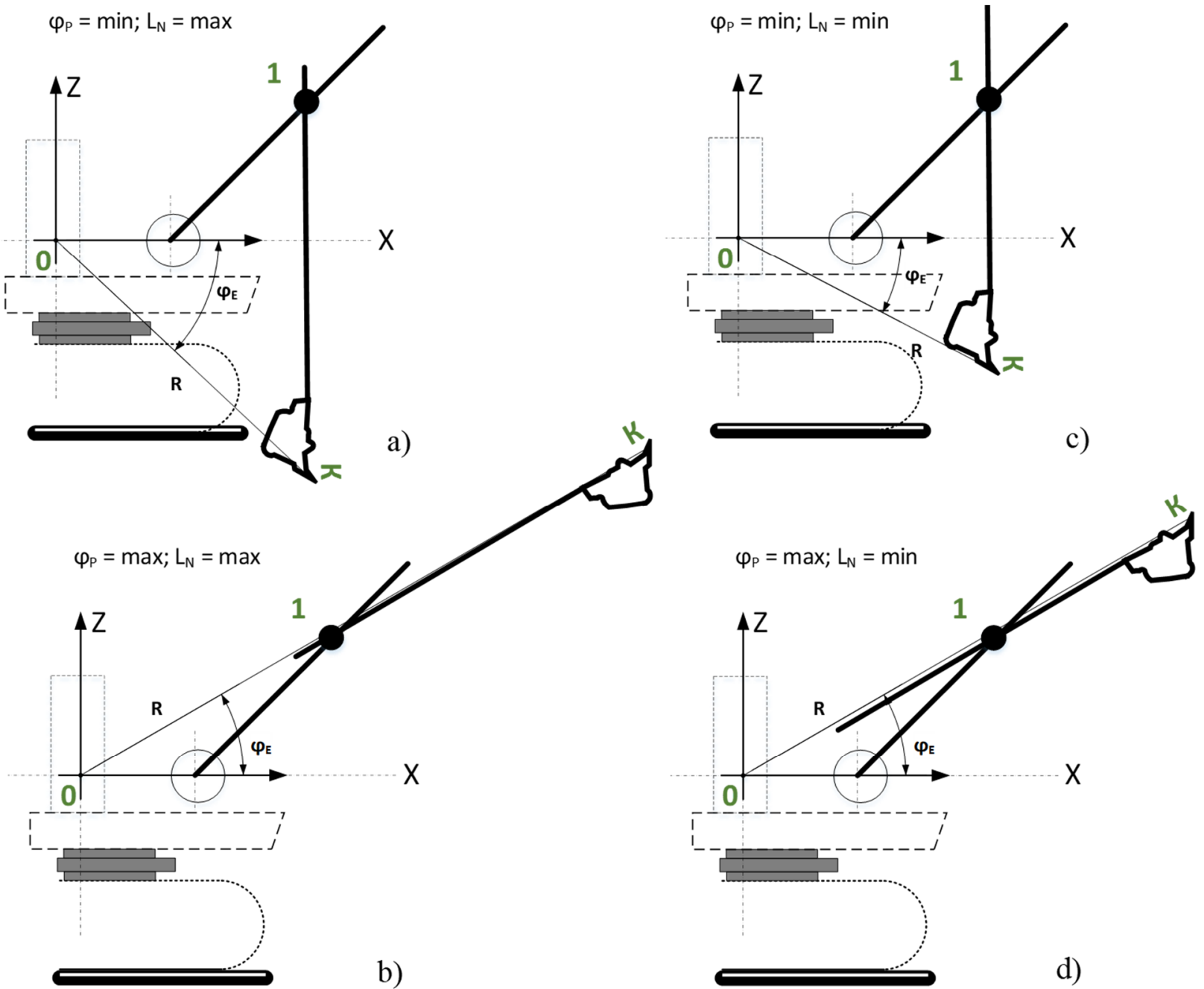

Fig. 4. Diagram of the mutual arrangement of the boom and dipper stick of an power shovel at various limiting values of the ascent angle of the dipper stick $\varphi_{P}$ and linear movement of the dipper stick $L_{N}$ : a) $\left.\varphi_{P}=\min ; L_{N}=\max ; \mathrm{b}\right) \varphi_{P}=\max ; L_{N}=\max$; c) $\varphi_{P}=\min ; L_{N}=\min ;$ d) $\varphi_{P}=\max ; L_{N}=\min$. 
Since the working bodies of the excavator make two different rotational movements, it is most natural to consider the movement of the working bodies of the excavator in a spherical coordinate system. The center of the spherical coordinate system of the excavator is located at point $\mathrm{O}$ on the platform rotation axis at a height equal to the height of the boom heel attachment, Fig. 5, Fig. 2.

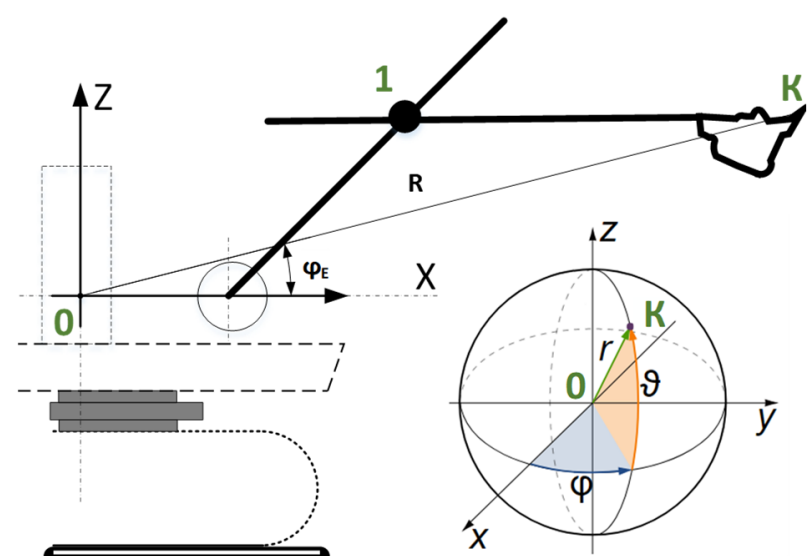

Fig. 5. Spherical coordinate system associated with the power shovel.

In this case, the spherical coordinate $\varphi$ will be equal to the angle of rotation of the power shovel revolving deck $\varphi_{R}$, the spherical coordinate $r$ will be equal to the length of the segment $0 K$, the spherical coordinate $\vartheta$ will be equal to the angle $K 0 X$ (angle $\varphi_{E}$ ).

The traditional way to derive kinematic equations for backhoe/excavator or generic robots is to start with Denavit-Hartenberg parameters and transformation matrices [15]. In this paper, a less traditional approach will be used to take advantage of the fact that the stick and bucket move in a plane that is rotated by the swing joint (see Fig. 4). Taking advantage of this fact, the position vectors can first be derived using spherical coordinates and then converted into Cartesian coordinates (Fig. 5). With this location of the center of the coordinate system and the accepted direction of the coordinate axes of the orthogonal Cartesian coordinate system, the level of the excavator is characterized by a negative value of the coordinate $Z$.

\section{Solving the direct problem of power shovel kinematics}

It is necessary to determine the Cartesian coordinates of the position of the digging point $K(X, Y, Z)$ according to the specified values of the control coordinates of the excavator - the linear movement of the shovel $L_{N}$, the angle of the boom $\varphi_{P}$, the angle of rotation of the platform $\varphi_{R}$.

Consider how the coordinates $r$ and $\vartheta$ of the spherical coordinate system are related to the lift angle $\varphi_{P}$ and linear movement of the shovel $L_{N}$.

Let's define the coordinates of the point $K K$ in the coordinate system $Z 0 Y$.

$$
\left\{\begin{array}{l}
K_{X}=R_{0}+L_{A N} \cos \left(\varphi_{A}\right)+\left(L_{N}+N_{1}\right) \cos \left(\varphi_{P}\right) \\
K_{Z}=L_{A N} \sin \left(\varphi_{A}\right)+\left(L_{N}+N_{1}\right) \sin \left(\varphi_{P}\right)
\end{array}\right.
$$

Then the spherical coordinates of the point $\mathrm{K}$ can be determined as follows:

$$
\begin{aligned}
& r=\sqrt{K_{X}^{2}+K_{Z}^{2}} \\
& \vartheta=\arctan \left(K_{Z} / K_{X}\right)
\end{aligned}
$$

The transition from a spherical coordinate system to three-dimensional Cartesian coordinates is carried out using the well-known expressions:

$$
\left\{\begin{array}{l}
X=r \cos (\vartheta) \cos \left(\varphi_{R}\right) \\
Y=r \cos (\vartheta) \sin \left(\varphi_{R}\right) \\
Z=r \sin (\vartheta)
\end{array}\right.
$$

Formulas (1-3) give us a closed solution to the direct problem of excavator kinematics and determine the equations for the transformation of the excavator control coordinates $\left(L_{N}, \varphi_{R}, \varphi_{P}\right)$ to the Cartesian coordinates of the digging point $(X, Y, Z)$.

\section{Solution of the inverse problem of power shovel kinematics}

It is necessary to determine the excavator control coordinates $\left(L_{N}, \varphi_{R}, \varphi_{P}\right)$ using the specified Cartesian coordinates of the position of the digging point .

The transition to spherical coordinates from Cartesian coordinates is carried out using the well-known expressions:

$$
\left\{\begin{array}{l}
\varphi_{R}=\arctan \frac{Y}{X} \\
\vartheta=\arctan \frac{Z}{\sqrt{X^{2}+Y^{2}}} \\
r=\sqrt{X^{2}+Y^{2}+Z^{2}}
\end{array}\right.
$$

Using equations (2), we obtain the following relations:

$$
\left\{\begin{array}{l}
K_{X}=\frac{1}{\sqrt{1+\tan ^{2}(\vartheta)}} \\
K_{Z}=\frac{\tan (\vartheta)}{\sqrt{1+\tan ^{2}(\vartheta)}}
\end{array}\right.
$$

And finally, based on equations (1), we get the follows:

$$
\begin{aligned}
\varphi_{P} & =\arctan \frac{K_{Z}-L_{A N} \sin \left(\varphi_{A}\right)}{K_{X}-R_{0}-L_{A N} \cos \left(\varphi_{A}\right)} \\
L_{N} & =\frac{K_{X}-R_{0}-L_{A N} \cos \left(\varphi_{A}\right)}{\cos \left(\varphi_{P}\right)}-N_{1} \\
\varphi_{R} & =\arctan \frac{Y}{X}
\end{aligned}
$$

When solving the inverse problem of power shovel kinematics, it is necessary to take into account that not all points in space $(X, Y, Z)$ are reachable, which is associated with the existence of design constraints on the control coordinates of the excavator.

Therefore, equations (4-6) must be supplemented with the following restrictions: 


$$
\left\{\begin{array}{l}
L_{N \min } \leq L_{N} \leq L_{N \max } \\
\varphi_{P \min } \leq \varphi_{P} \leq \varphi_{P \max } \\
\varphi_{R \min } \leq \varphi_{R} \leq \varphi_{R \max }
\end{array}\right.
$$

Equations (4-6) subject to constraints (7) gives us a closed solution for the inverse problem of excavator kinematics.

\section{Computational experiment}

To validate the obtained expressions, a number of calculations were performed using the example of the EKG-8I excavator. The overall dimensions of this excavator used in the calculations are shown in Table 1.

Fig. 6 shows the results of calculations of the working area of the EKG-8I excavator, which shows the entire area of space reachable by the excavator bucket under the constraints indicated in Table 1. The working area of the EKG-8I excavator has a complex spatial shape, limited in the front and rear by areas of the sphere.

Using the obtained expressions, a number of trajectories were calculated for moving the bucket after the end of digging from point 1 to point of unloading the bucket 2 (Fig. 7).

Trajectory 1 is obtained with the uniform motion of all excavator mechanisms. The Trajectory 2 was obtained by implementing a rectilinear movement from point 1 to point 2. Since a part of this trajectory went beyond the limits of the excavator's working area, a curvilinear section was formed in its middle part, corresponding to movement along the border of the working area.

Table 1. Dimensions of the power shovel EKG-8I

\begin{tabular}{|l|c|}
\hline \multicolumn{1}{|c|}{ Parameter } & Value \\
\hline Boom length, m & 13.35 \\
\hline$\varphi_{A}$ - Tilt angle of boom, deg & 47 \\
\hline Dipper stick length, m & 11.425 \\
\hline Dipper stick stroke, m & 4.3 \\
\hline $\begin{array}{l}R_{0}-\text { Distance from the revolving deck rotation axis to } \\
\text { the boom heel attachment point, m }\end{array}$ & \\
\hline$N_{1}$ - Dipper stick length minus dipper stick stroke, $\mathrm{m}$ & \\
\hline $\begin{array}{l}L_{A N}-\text { Distance from the point of attachment of the } \\
\text { boom heel to the saddle bearing, } \mathrm{m}\end{array}$ & \\
\hline $\begin{array}{l}L_{N \min }-\text { The minimal value of dipper handle position, } \\
\text { m }\end{array}$ & 0 \\
\hline $\begin{array}{l}L_{N \max }-\text { The maximal value of dipper handle position, } \\
\text { m }\end{array}$ & 4,3 \\
\hline $\begin{array}{l}\varphi_{\text {Pmin }}-\text { The minimum value of the angle of the } \\
\text { hoisting mechanism, deg }\end{array}$ & -90 \\
\hline $\begin{array}{l}\varphi_{\text {Pmax }}-\text { The maximal value of the angle of the } \\
\text { hoisting mechanism, deg }\end{array}$ & 45 \\
\hline $\begin{array}{l}\varphi_{\text {Tmin }}-\text { The minimum value of the swing angle of the } \\
\text { power shovel revolving deck, deg }\end{array}$ & 0 \\
\hline $\begin{array}{l}\varphi_{\text {Tmax }}-\text { The maximum value of the swing angle of } \\
\text { the power shovel revolving deck, deg (determined by } \\
\text { the parameters of the power shovel working area) }\end{array}$ & 120 \\
\hline
\end{tabular}

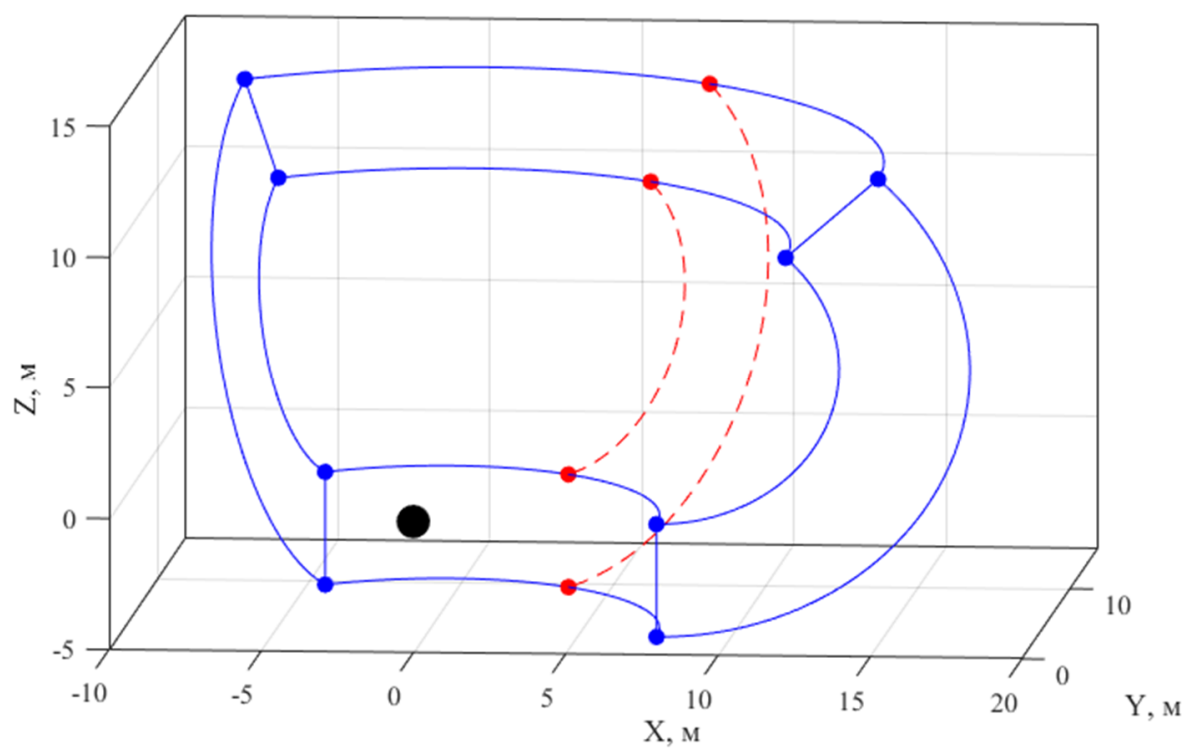

Fig. 6. Working area of the power shovel EKG-8I.

Trajectory 3 was obtained by sequentially turning the platform and then lowering the bucket to point of unloading 2.

The implementation of Trajectory 1 and Trajectory 2 requires the simultaneous coordinated operation of the electric drives of all the main mechanisms of the excavator, which may require high qualifications of the operator. Trajectory 3 is ensured by the sequential operation of the electric drives of the main mechanisms of the excavator.
The calculations showed that the length of these trajectories differs significantly: from $25 \mathrm{~m}$ (Trajectory 2) to $33 \mathrm{~m}$ (Trajectory 3 ), which is $32 \%$.

\section{Conclusion}

The analysis of the mechanical structure of a mining bucket excavator was carried out, which made it possible to solve the inverse problem - according to a given trajectory of movement of the working body, taking into account technological limitations, at each point, the coordinates of individual actuators were calculated. The 
obtained trajectories of movement show the available possibilities for optimizing the operation of mining excavators, in particular, for minimizing the length of trajectories. However, it should be borne in mind that only the length of the trajectory cannot serve as an optimization criterion, since it does not take into account the speed of movement of the bucket along the trajectory and the associated energy costs of individual mechanisms, in which not only the speeds and accelerations but also the equivalent moments of inertia change during the movement.

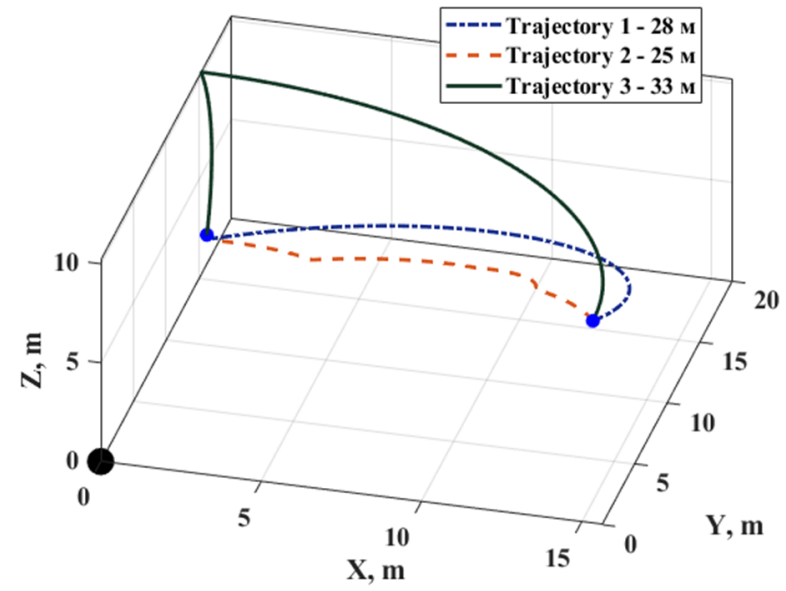

Fig. 7. Trajectories for moving the bucket after digging to the point of bucket unloading

The analysis of the energy costs of individual mechanisms, which is planned in the future, depending on the specified trajectory of the working body, will serve as the basis for optimizing the energy consumption and productivity of mining excavators when performing a full working cycle and can automate the processes of controlling the position of its individual mechanisms.

\section{References}

1. B.C. Kwaginidze, Ju.A. Antonow, W.B. Korezkij, N.N. Tschupejkina, Ekckawatory na kar'erach. Konctrukzii, jekcpluatazija, ractschet. (M., Gornaja kniga, 409, 2009).

2. N. Kyura, H. Oho, IEEE/ASME Transactions on Mechatronics, Mechatronics an industrial perspective, 1, 6 (1996).

3. A.E. Kosjaruk, Problemy sozdanija perspektiwnych sistem elektropriwodow i NKU w gornych maschinach, Sowerschenctwowanie sistem uprawlenija elektrooborudowaniem kar'ernych gornych maschin, 1, 5, (2006)

4. R.P. Bishop, CRC Press. Taylor \& Francis Group, Mechatronics : An Introduction, 285 (2006)

5. Stanley M. Shinners, Lockheed Martin Federal Systems John Wiley \& Sons, Inc., 1998 ISBN: 0-47124906-8

6. N K Kuznetsov et al, J. Phys.: Conf. Ser., Investigation of efficiency of electric drive control system of excavator traction mechanism based on feedback on load, 1, 7 (2018)
7. R.H. Bichop, New York, CRC Press, Mechatronic Systems, Sensors, and Actuators: Fundamentals and Modeling, 712 (2007)

8. J. Kitzig, G. Bumiller, IEEE International Instrumentation and Measurement Technology Conference, Evaluation of Power Quality Measurement System Concept using an experimental setup, 1, 7, (2019)

9. C. Wu Keng, Academic Press, Switch-Mode Power Converters, Chapter 10 - AC-DC Power-Factor Correction Supplies, (2006)

10. J. T. Betts, Philadelphia, Pennsylvania: SIAM Press, Practical Methods for Optimal Control Using Nonlinear Programming (2nd ed.) (2010).

11. V. Tytiuk, I. Lutsenko, I. Oksanych, Zh. Rozhnenko Eastern European Journal of Enterprise Technologies. 90, 9 (2017)

12. W.M. Zaw'jalow, I.Ju. Semykina, Izwestija Tomskogo politechnitscheckogo uniwersiteta, Matematitscheckaja model' mechanitscheckoj tschacti wsaimocwjasannych jelektropriwodow napora i pod\#ema kar'ernogo jekckawatora. 310, 4, (2007)

13. V. Tytiuk, M. Baranovskaya, D. Meleshko, O. Chornyi, Electromechanical and energy saving systems, Mathematical modeling of group drives push and lift electric excavator mechanisms, 33, 7 (2016)

14. B.M. Wilamowski, New York, CRC Press, Control and Mechatronics (The Industrial Electronics Handbook), 728, (2011)

15. J. G. Frankel, MS thesis. The Georgia Institute of Technology, G.W. Woodruff School of Mechanical Engineering, Development of a Haptic Backhoe Testbed (2004) 